\title{
Least-Cost Modelling and Landscape Ecology: Concepts, Applications, and Opportunities
}

\author{
Thomas R. Etherington ${ }^{1,2,3}$
}

Published online: 2 June 2016

(C) Springer International Publishing AG 2016

\begin{abstract}
The concept of nearness and that nearer things are more connected is useful in quantifying a variety of geographical patterns and processes, including ecological connectivity between geographic locations. In some ecological systems connectivity does not follow nearness relations defined by Euclidean distances, so distance must be measured another way. Least-cost modelling is a technique that can incorporate traversal costs across a landscape to measure the least-cost distance between locations as a function of both the distance travelled and the costs traversed. There has been a significant increase in the interest and use of least-cost modelling by ecologists in the last decade. However, perhaps because early applications of least-cost modelling in ecology tended to cite the method with reference to geographic information system software rather than the geographical science literature, ecologists are not currently making full use of available least-cost modelling techniques that have continued to develop. This review aims to describe the concepts of least-cost modelling, demonstrate current applications of least-cost modelling in landscape ecology, and to suggest future opportunities by linking the ecological application of least-cost modelling with recent geographical science developments from which leastcost modelling originally developed.
\end{abstract}

This article is part of the Topical Collection on Methodological Development

Thomas R. Etherington

t.etherington@kew.org

1 Royal Botanic Gardens Kew, Wakehurst Place, West Sussex, UK

2 Department of Zoology, University of Oxford, Oxford, UK

3 School of Environment, The University of Auckland, Auckland, New Zealand
Keywords Connectivity $\cdot$ Cost-distance $\cdot$ Dispersal · Distance $\cdot$ GIS $\cdot$ Movement

\section{Introduction}

The question of what is near is a core concept of spatial information [1], and is emphasised by Tobler's first law of geography that states "everything is related [connected] to everything else, but near things are more related [connected] than distant things" [2, p. 236]. This association between nearness and the degree of relation or connection can be used to quantify a variety of geographical patterns and processes including movement between geographic locations [3], which has ecological implications relating to habitat fragmentation [4], invasive species [5, 6], and epidemiology [7, 8].

Measuring nearness to quantify connections and infer movement potential in ecology began with the theory of island biogeography, which predicted that islands nearer to population sources in terms of straight-line Euclidean distance had greater immigration rates [9]. Later research applied the same straight-line distance approach to nearness using a patchmatrix landscape model [10] to demonstrate that patches nearer sources were more likely to be occupied by a species $[11,12]$. However, the importance of landscape structure on connectivity and, therefore, movements across landscapes was soon theorised [13] and demonstrated [14]. So, in some ecological systems, connectivity, and therefore, movement, does not follow nearness relations defined in Euclidean space. However, this does not invalidate Tobler's first law of geography, but rather means that nearness needs to be measured in geographic space using another approach such as least-cost distance [3].

Least-cost (or cost-distance) modelling is a quantitative geographic technique to measure nearness that was developed 
in transport geography where there was a need to be able to identify optimal routes across landscapes with varying costs of travel. Using the analogy of light refraction through different mediums, Warntz $[15,16]$ provided early examples of how to calculate a route of least-cost between locations separated by regions of differing transport costs, and showed that least-cost routes radiating out from a central location could be mapped as a continuous surface. At a similar time McHarg [17] presented a map overlay approach that combined geographic information about not only transport costs, but also social and environmental costs, to determine a region within which a highway could be located that balanced positive and negative impacts. While the work of Warntz [15, 16] and McHarg [17] established the basic principles of calculating a least-cost route and incorporating a diversity of geographic costs respectively, the efficient and repeatable application of these principles was only possible with the adoption of computer technology. Turner and Miles [18] developed a computerised approach that combined the principles of Warntz [15, 16] and McHarg [17] to produce the first example of what we would now recognise as least-cost modelling. Turner and Miles [18] presented a process that first created a gridded cost-surface that was the sum of geographical costs multiplied by associated weights and then used a shortest-path graph theory algorithm to determine the optimum route between two locations.

Although least-cost modelling was developed in the context of transport geography, as it addressed the fundamental geographical question of what is near, least-cost modelling was included within the earliest developments of geographic information system (GIS) software [19]. It was from GIS software that ecologists discovered leastcost modelling and were able to demonstrate that leastcost distance measures of nearness outperformed simpler Euclidean distance based measures of nearness in explaining patch occupancy as a function of ecological connectivity $[20,21]$. Given the potential of the approach, following the first formal introduction of least-cost modelling in ecology [22] there has been a significant increase in the interest and use of least-cost modelling by ecologists. However, perhaps because early applications of least-cost modelling in ecology tended to cite the method with reference to GIS software rather than the geographical science literature, ecologists are not currently making full use of available least-cost modelling techniques that have continued to develop. This review aims to describe the concepts of least-cost modelling, demonstrate current applications of least-cost modelling in landscape ecology, and to suggest future opportunities by linking the ecological application of least-cost modelling with recent geographical science developments from which least-cost modelling originally developed.

\section{A Least-Cost Algorithm}

Least-cost modelling has been described using a variety of different algorithms that may be implemented in any given software. Additionally, the terminology used to describe leastcost modelling is used inconsistently in the literature. Therefore, any discussion of least-cost modelling needs to be preceded with a formal definition in order to clarify the points of discussion. I describe a least-cost algorithm $[19,23]$ that from my experience is the most widely applied - although researchers are advised to ensure that they understand the implementation of least-cost modelling within their own software.

Least-cost modelling is based upon a GIS raster called a cost-surface (otherwise known by combinations of: cost, friction, permeability, or resistance and layer, grid, map, raster, or surface). The values within a cost-surface are used to represent the per unit distance cost associated with traversing different parts of a landscape (Fig. 1a). The accumulated cost of traversal is calculated as the product of the cost and distance traversed. Using an example of minimising the monetary costs of transport for which least-cost modelling was developed, moving $100 \mathrm{~m}$ through a region with a cost of $\$ 10 \mathrm{~m}^{-1}$ results in an accumulated-cost of $\$ 1000=\$ 10 \mathrm{~m}^{-1} \times 100 \mathrm{~m}$.

Although least-cost modelling was conceived to minimise the monetary costs of transportation, costs could also be expressed in other absolute units such as energy $\left(\mathrm{J} \mathrm{m}^{-1}\right)$ or time $\left(\mathrm{s} \mathrm{m}^{-1}\right)$ so that least-cost modelling results can also be expressed in absolute units of energy ( $\mathrm{J}$ ) or time (s). However, due to uncertainty about ecological movement, and the desire to incorporate multiple ecological processes such as energy expenditure, behavioural aversion, and mortality, which affect the choice and success of movement, ecological studies tend to use a relative and unitless measure of cost. Relative unitless costs are still expressed per unit distance, but result in a unitless accumulated-cost of traversal. For example, moving $100 \mathrm{~m}$ through a region with a relative cost of $10 \mathrm{~m}^{-1}$ results in an accumulated-cost of $1000=10 \mathrm{~m}^{-1} \times 100 \mathrm{~m}$. As most ecological studies use relative unitless measures of cost, this is the approach used by the illustrative examples within this review.

To calculate least-cost routes across a cost-surface, most GIS least-cost modelling approaches convert the raster cost-surface into a weighted lattice graph for processing. The centroids of non-null cells become the vertices, and weighted edges are created between orthogonally and diagonally neighbouring vertices (Fig. 1b). The edge weights (e) are the accumulated-cost between neighbouring vertices $(a, b)$ defined as the product of the mean cost value $(c)$ and the Euclidean distance $(d)$ between the centroids of the neighbouring cells:

$e_{a, b}=\frac{c_{a}+c_{b}}{2} \times d_{a, b}$ 
Fig. 1 An example of the leastcost modelling algorithm. (a) A hypothetical cost-surface based on relative costs and a set of locations of interest. If the costsurface is ignored then location A is equally connected to locations $\mathrm{B}$ and $\mathrm{C}$ and the $\mathrm{A}-\mathrm{B}$ and $\mathrm{A}-\mathrm{C}$ distances are both $16 \mathrm{~km}$. (b) Result of converting the raster cost-surface into a lattice graph. Using A as a source location, Dijkstra's Algorithm is applied to create a Dijkstra tree that finds the shortest-paths through the graph, and is shown here when the accumulated-cost has reached (c) 10,000 , (d) 60,000 , and (e) the whole landscape. (f) The results of Dijkstra's Algorithm are then converted into a raster least-cost surface and vector least-cost paths. Having incorporated the information from the cost-surface locations $\mathrm{B}$ and $\mathrm{C}$ are not equally connected to $\mathrm{A}$ as the least-cost distance for A-B is nearly eight times larger than the least-cost distance for A-C
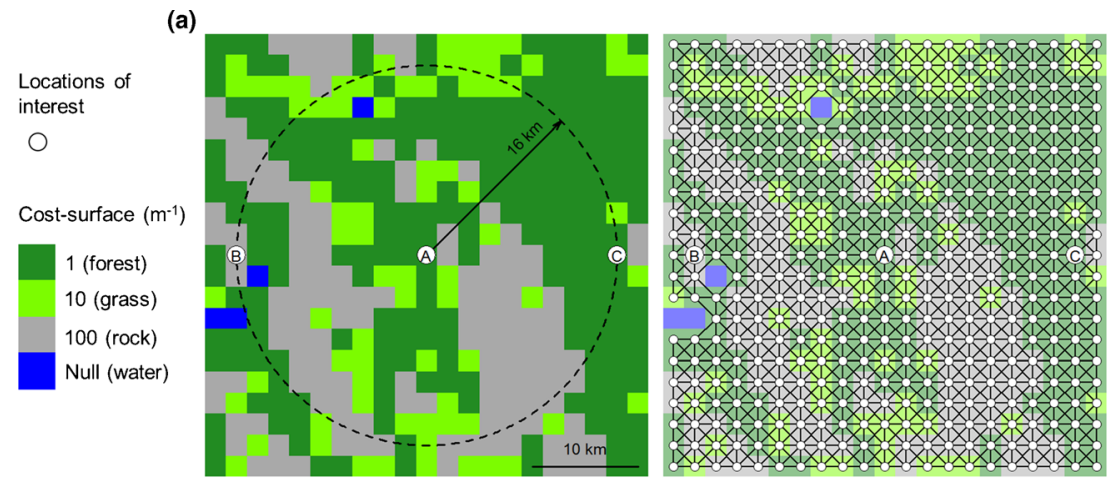

(b)
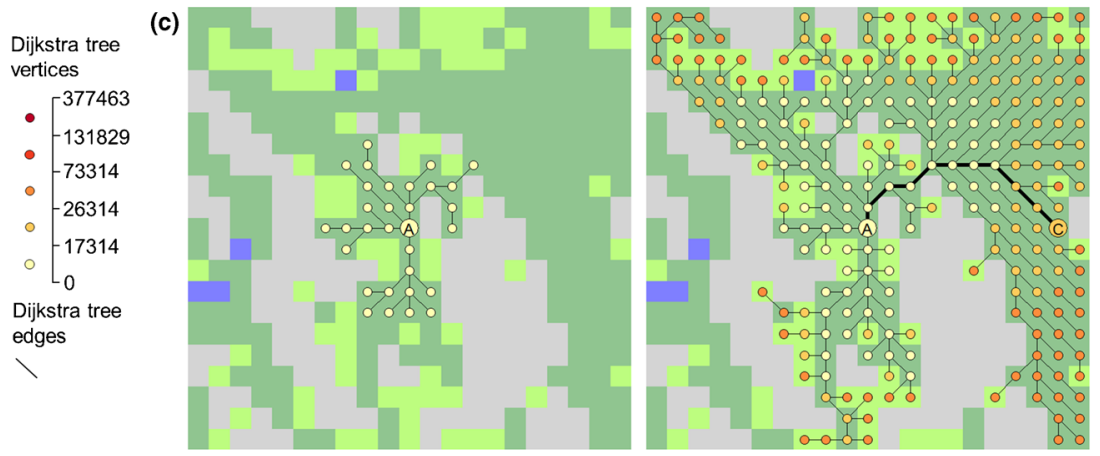

(d)

Dijkstra tree vertices

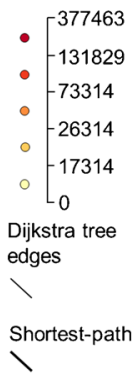
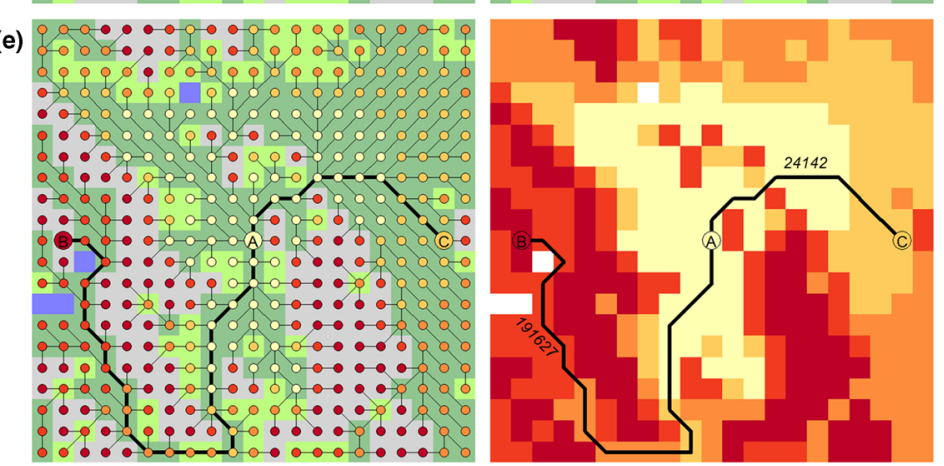

(f)

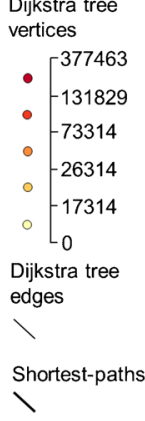

Least-cost path
Least-cost surface

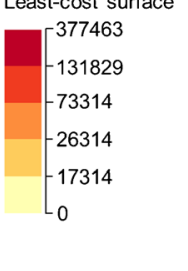

With this weighted lattice graph data structure established, the accumulated-cost for a path between any two vertices on the graph can be measured as the sum of the edge weights along that path. However, least-cost modelling uses graph theory shortest-path algorithms such as Dijkstra's Algorithm [24] to find a least-cost distance $(l c d)$ between a start vertex $(i)$ and an end vertex $(j)$ that is the minimum possible sum of edge weights between vertices along the shortest-path:

$l c d_{i, j}=\min \sum_{i=1}^{j-1} e_{i, i+1}$

Dijkstra's Algorithm works in an iterative vertex by vertex spreading manner [25] and results in a Dijkstra tree that branches out one vertex at a time to find the shortest paths from the source vertex, or tree root, to the other vertices (Fig. 1c-e). The accumulated sum of edge weights leading to each vertex of the Dijkstra tree are converted into a raster least-cost (or cost-distance, accumulated cost) surface, and a
Dijkstra tree branch can be converted into a vector least-cost path (Fig. 1f). The least-cost distances associated with these outputs are a measure of nearness that optimises the Euclidean distance travelled and the costs traversed, while the least-cost path shows the route of maximum efficiency from the source cell to any other individual end cell. As the least-cost distances incorporate landscape costs to movement (Fig. 1f), they are able to differentiate the nearness between locations that might otherwise be considered equally near if the landscape costs were ignored (Fig. 1a).

It is important to note that while least-cost paths can be used to help visualise the results of least-cost modelling, some ecological studies have used the length of a least-cost path in metres as a measure of connectivity. However, simulations have demonstrated that least-cost path length can be a misleading measure of connectivity in some landscapes, and that leastcost distances should always be used as a connectivity measure, with least-cost paths simply being a way to evaluate visually the assumptions underlying the least-cost modelling [26]. 


\section{Cost-Surfaces}

\section{Cost-Surface Construction}

The basic construct of a cost-surface has not changed since its inception and involves the summation of a series of raster map layers that are each multiplied by a weighting factor [18]. A cost-surface can be defined using a local map algebra approach [27] for which the cost $(c)$ is the sum of a set of raster landscape features $(S)$ for which each raster with values ranging from $0-1$ $(r)$ has been multiplied by its associated weight $\left(w_{r}\right)$ :

$c=1+\sum_{r \in S} r \times w_{r}$

The use of Eq. 3 has a strong theoretical foundation. In the absence of any input raster landscape features, or when all weights are equal to zero, the cost-surface will have a uniform value of one. This results in the accumulated cost between neighbouring cells (Eq. 1) equalling the Euclidean distance and least-cost modelling measuring distance in terms of Euclidean distances.

Of course, for raster landscape features to be combined in this way they need to be in comparable units. However, this is problematic for ecological studies as the cost to traverse different landscape features will be measured in a variety of different units, for example traffic volume to traverse roads, elevation to traverse mountains, or tree density to traverse forests. Therefore, to integrate this wide range of landscape features, the values for each raster need to be initially rescaled to a common range. As some landscape features are binary in form, being either present or absent, the rescaling for continuous landscape features should range from $0-1$ in order to be comparable. For both binary and continuous landscape features, values of zero indicate where there is no cost, and values of one indicate where there is a maximum cost for that particular landscape feature. Rescaling values to range from $0-1$ then means that the weights applied are comparable as a landscape feature with a weight twice that of another will have a cost that is twice that of another (Fig. 2a).
Fig. 2 (a) Construction of a costsurface through the combination of a set of raster layers with associated weights. Such costsurface construction assumes all raster layers have been rescaled to have values ranging from $0-1$ in order to be comparable. This rescaling can be achieved using either (b) a local function that is dependant only on the value for each raster cell or (c) a spatial function that incorporates distance (a)

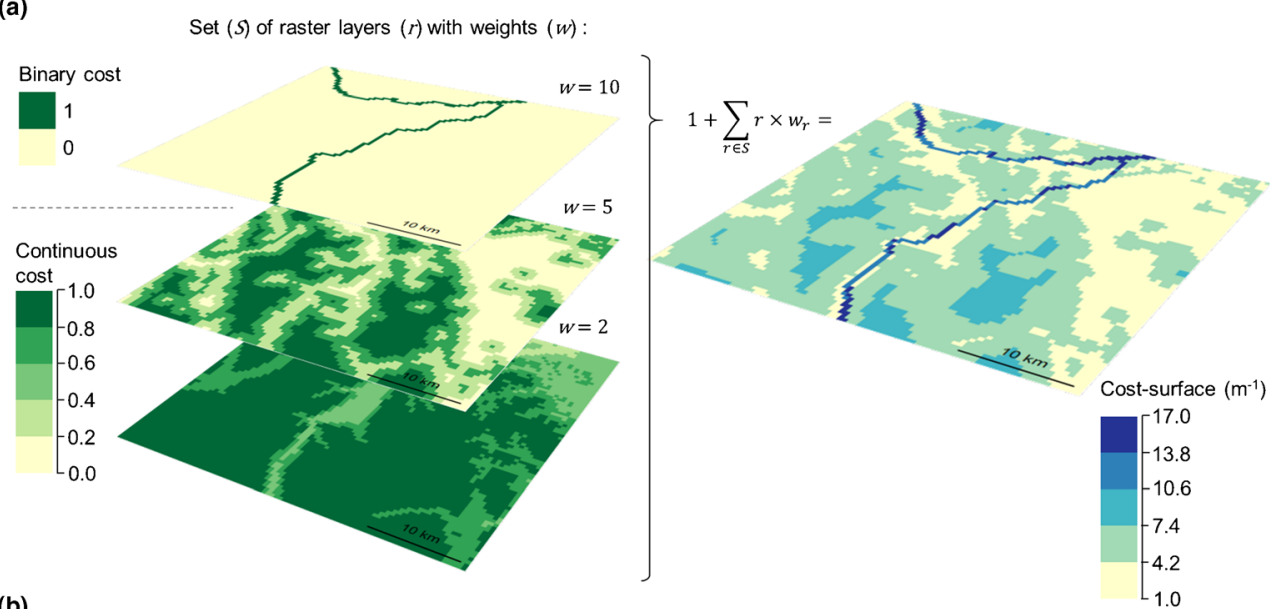

(b)
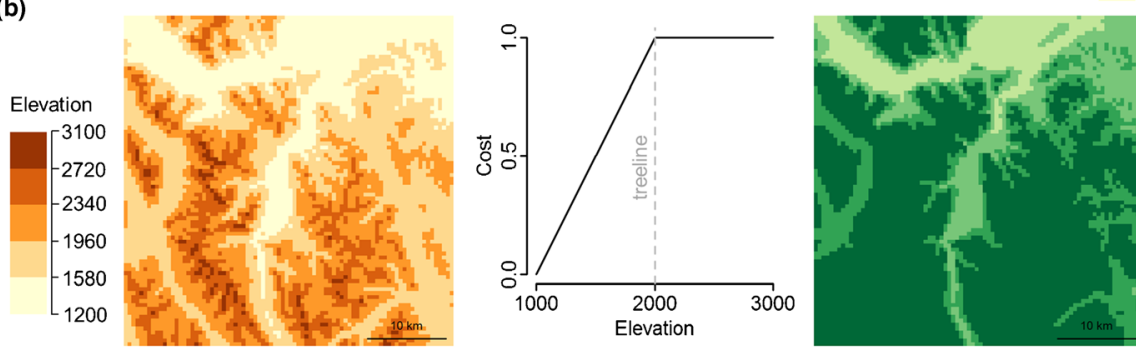

Rescaling raster layers to range 0 to 1

(c)

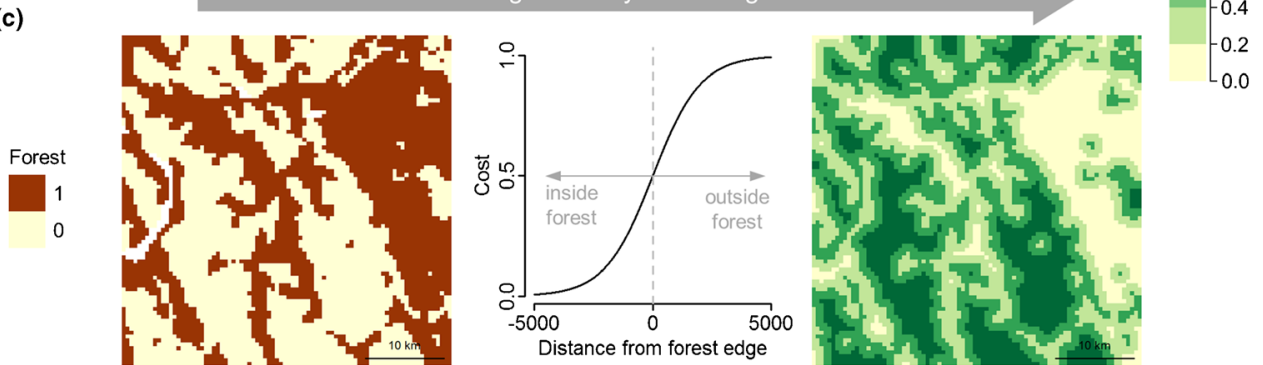


The multiplicative application of weights to raster landscape features in Eq. 1 assumes a linear function between an increase in weight and an increase in cost, but this may not always be the case as costs may increase exponentially or to an asymptote. Therefore, the rescaling of raster values to range 0-1 also provides an opportunity to incorporate more ecological realism into the cost-surface, as the rescaling can take a variety of forms that could be either local [28, 29] or spatial [30, 31]. For example, traversal cost might be assumed to increase with elevation, but only up to a certain point, such as the treeline, beyond which traversal costs might remain constant (Fig. 2b). Or for a forest organism, the traversal cost could be modelled as a function of distance from forest edge, with costs rapidly increasing for locations at or beyond the forest's edge (Fig. 2c).

The inclusion of linear features in a raster cost-surface needs particular care. As least-cost modelling establishes diagonal links between cells (Fig. 1b), in order for linear features to act as obstacles to movement within the cost-surface, the cells constituting a linear feature must be connected orthogonally. Solutions to ensure that this occurs include using very high resolution rasters [22], applying a post-rasterisation gap filling algorithm [32], and using rasterisation techniques that ensure orthogonality of the rasterised linear features [33]. Representing a linear feature using a raster data structure can over-estimate traversal costs as the linear feature will become at least one cell wide in the cost-surface, but may in fact be much narrower than one cell in reality. Therefore, another option is to use a vector-based approach that applies the cost of a linear feature to the graph edges by finding those edges that have a spatial intersection of cell links with linear features [34].

The choice of scale, in terms of both grain and extent, has fundamental effects on spatial analyses [35] including least-cost modelling (Fig. 3). To avoid issues associated with extent, researchers should ensure a suitably large buffer region around the locations of interest. If all the least-cost distances between locations of interest are smaller than the least-cost distances from the locations of interest to the edge of the cost-surface, then the leastcost modelling will be free from any effects of increasing extent further. The issue of grain is more problematic, as the appropriate grain will be species and landscape specific, and at present there are no guidelines available to guide grain selection for least-cost modelling. Given this uncertainty, researchers should probably try to use the smallest possible grain size supported by their input data, as simulations have shown that smaller grains produce better results [36]. Using the smallest grain supported by the input data will also avoid the issue of choosing a method of data aggregation that will also influence leastcost modelling results [37].
Fig. 3 The effects of changing scale on least-cost modelling. Changing grain size always produces different least-cost paths, as shown by the least-cost paths A-B and A-C. By comparison, changes in extent size only affect least-cost paths that could be shorter. For example least-cost path A-C is not affected by changes in extent at either grain size, but least-cost path A-B is affected by changes in extent at both grain sizes as the increase in extent enables shorter least-cost paths

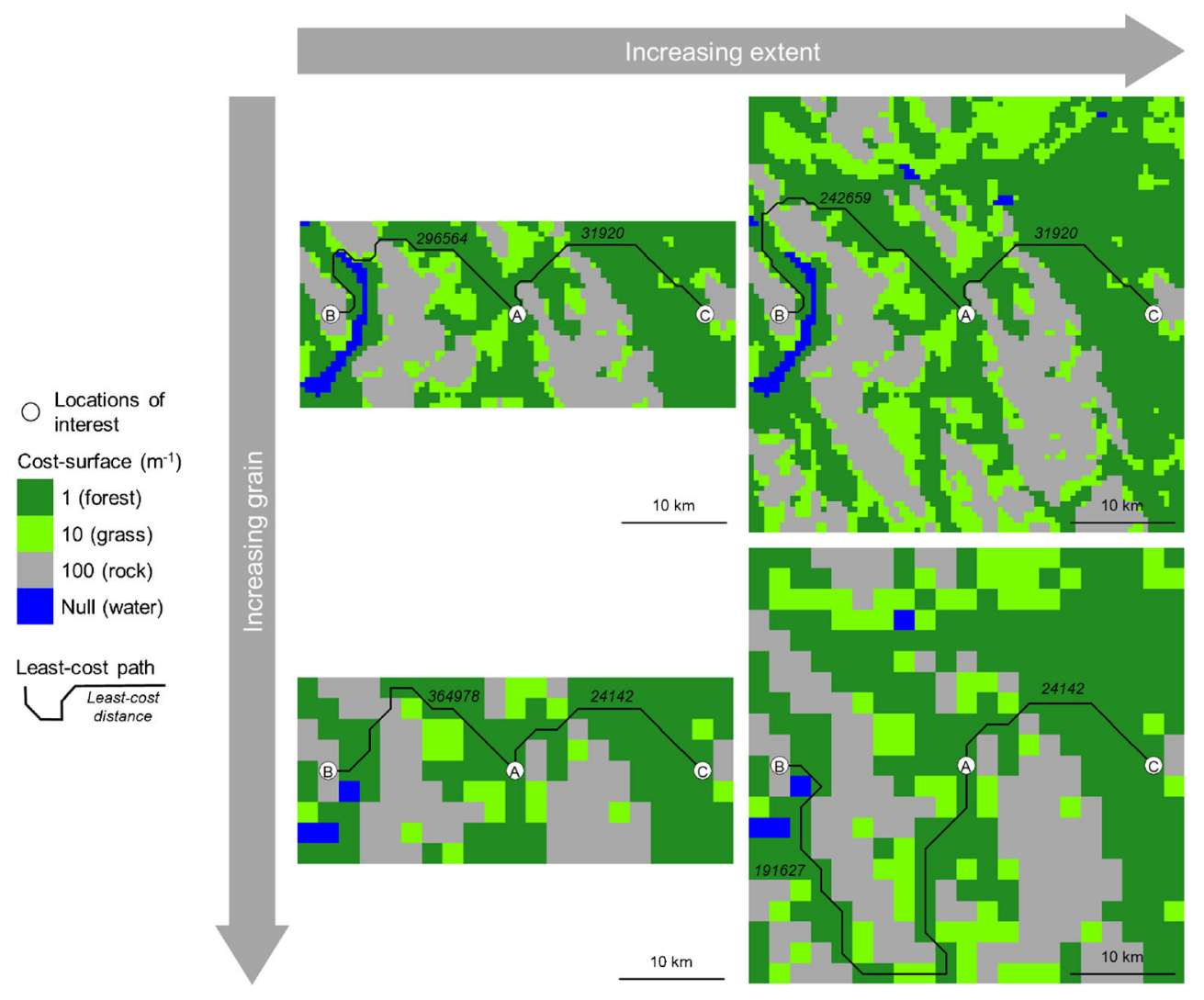




\section{Cost-Surface Selection}

Selecting an ecologically meaningful cost-surface is by far the most challenging aspect for ecological applications of leastcost modelling. Given the difficulties in studying organism movement, ecological least-cost modelling has most often been conducted solely on the basis of expert opinion [38••]. Such expert opinion is derived either by the researchers within a study group [27, 39-41] or can be elicited from a wider group using more formal elicitation approaches [39, 42]. Expert opinion can be applied either for specific species or by creating generic focal species that have movement characteristics of particular interest $[43,44]$.

Clearly, expert opinion approaches have limitations and potential biases, so where possible least-cost modelling should involve some form of ecological connectivity data. Currently, the most common way of incorporating connectivity data into an ecological least-cost modelling study is to use expert opinion to establish a set of candidate cost-surfaces, and then use landscape genetics to assess the quality of the candidate costsurfaces $[38 \bullet \bullet]$. Landscape genetics uses the genetic distance between populations or individuals as an estimate of connectivity between those locations [45]. The landscape genetics approach has become a very popular method for estimating connectivity, especially over large spatial extents, as genetic distances can be measured from an existing population, which avoids the need to record individual dispersal events that can be rare or difficult to observe. Genetic distances can then be compared to least-cost distances from a variety of costsurfaces to identify those cost-surfaces that produce leastcost distances that are a better fit to the landscape genetic data [46].

A variety of statistical techniques have been used to compare genetic and least-cost distances. Initially these comparisons were done using pair-wise genetic and least-cost distance matrices and Mantel tests [47]. However, there are concerns about the suitability of Mantel tests for this application [48] and other approaches based on spatial networks and information criterion have since been developed [28, 49]. However, as simulations have demonstrated that there is unlikely to be any one best statistical method for landscape genetics studies [50], researchers should carefully choose and justify their approach based on their specific data requirements and study objectives. An interesting alternative to conventional statistical approaches that has been suggested is to use machine learning techniques that could iteratively refine a cost-surface [46]. Machine learning techniques are designed to develop predictive models for complex and non-linear data [51] and provide an alternative to traditional statistical approaches used in landscape genetics that may be sensitive to violations of assumptions of independence, normality, and linearity [50]. Given the importance of machine learning in other fields of research [51], the application of machine learning methods for least- cost modelling is an opportunity that would benefit from further research.

While landscape genetics is a popular approach, genetic distances are not necessarily an ideal measure of connectivity in all ecological applications, as genetic distances are dependent not only on the movement process, but also on other factors such as survival and reproduction [46]. So while landscape genetics is currently the predominant quantitative approach applied by ecologists to select a cost-surface, there are other approaches that use occurrence, mark-recapture, and pathway movement data that in some circumstances may be more suitable for cost-surface selection [38••].

Given the complexities associated with linking field data and least-cost models, when developing new methods for cost-surface selection, ecologists may benefit from adopting a virtual ecology approach that uses simulation models to rigorously evaluate sampling schemes and analytical methods against a known truth [52•]. Using this approach ecological patterns could be created that are absolutely known to be a direct result of connectivity as defined by a hypothetical costsurface. Methodologies that could be applied to collect and analyse empirical field data can then be simulated to measure the ecological patterns and to estimate what the underlying cost-surface is expected to be. Using this kind of controlled modelling approach it should be possible to identify methods that are capable of selecting reliable cost-surfaces. Virtual ecologies from such simulations are now commonly used in developing methodologies for species distribution modelling [53] and have started to be applied to investigate methods within landscape genetics $[48,50]$.

\section{Ecological Applications of Least-Cost Modelling Outputs}

\section{Least-Cost Networks}

Some landscapes can be viewed as a network of interconnected habitat patches. These ecological networks can be represented by a landscape graph in which vertices represent habitat patches, and edges represent connections between neighbouring patches [54]. The landscape graph edges that represent the connections between patches can be weighted using least-cost distances to identify those patches that are more or less connected [40]. The resulting least-cost network (Fig. 4a), can then be analysed using a vast array of graph theory approaches to measure connectivity properties within the landscape graph [55], which can then be compared with ecological patterns such as species diversity or population persistence. Another approach to least-cost networks is to specify least-cost distances that represent limits to movement potential for processes such as foraging or dispersal and to buffer the habitat patches by these least-cost distances [43]. 
Fig. 4 Some examples of ecological applications of leastcost modelling. (a) The costsurface used in all the examples, plus a least-cost network of leastcost paths between neighbouring locations of interest. (b) A leastcost corridor and least-cost path between locations D and G. (c) Probability density functions fitted to dispersal observations measured in least-cost distances can be used to create dispersal distance and dispersal location kernels. (d) Application of the dispersal location kernel to show the probability of dispersing to other locations from a series of location. The dispersal location kernel was then used to create (e) a least-cost kernel density estimation based on locations of interest and (f) a least-cost catchment area isolation map
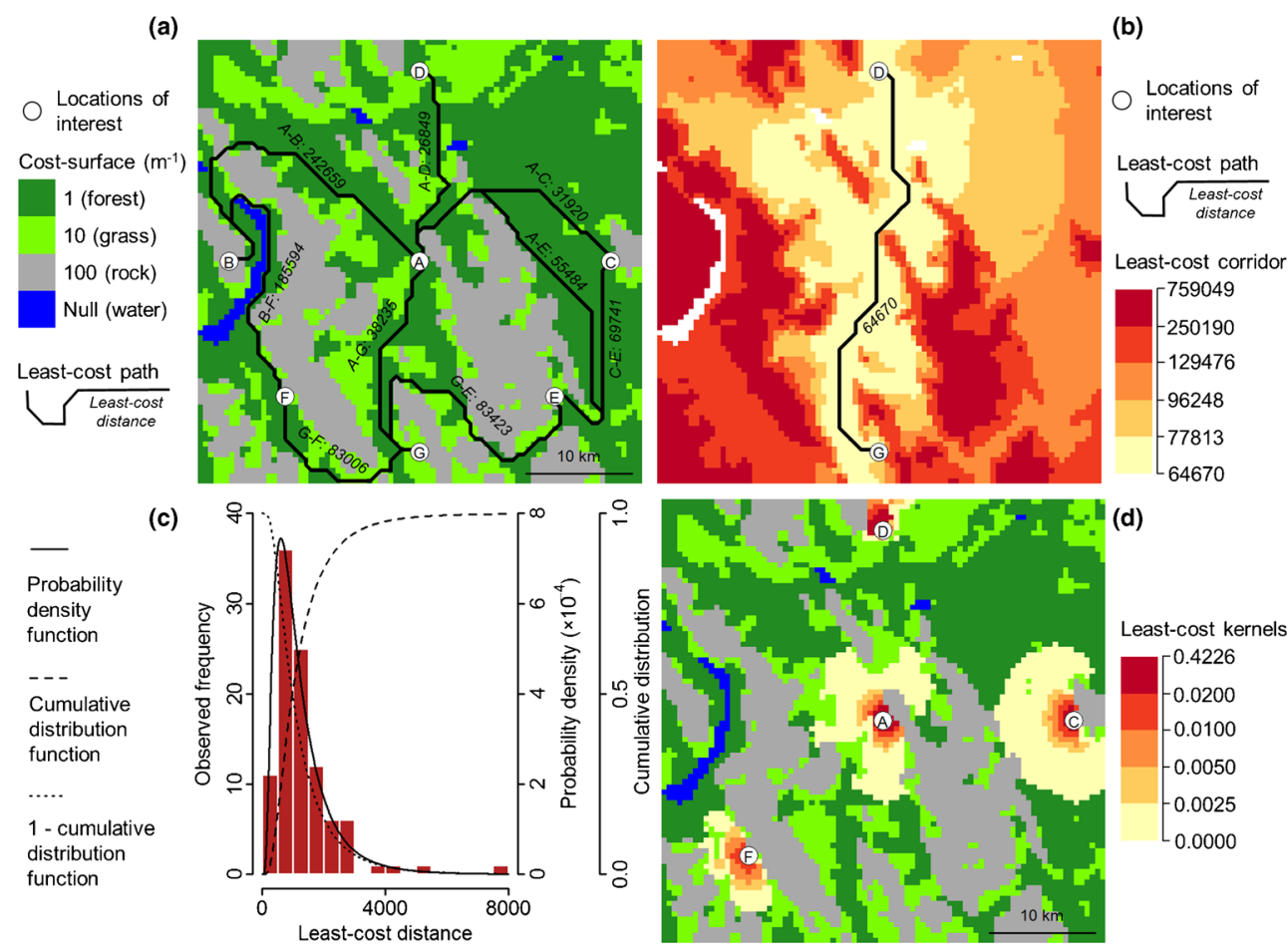

(e)
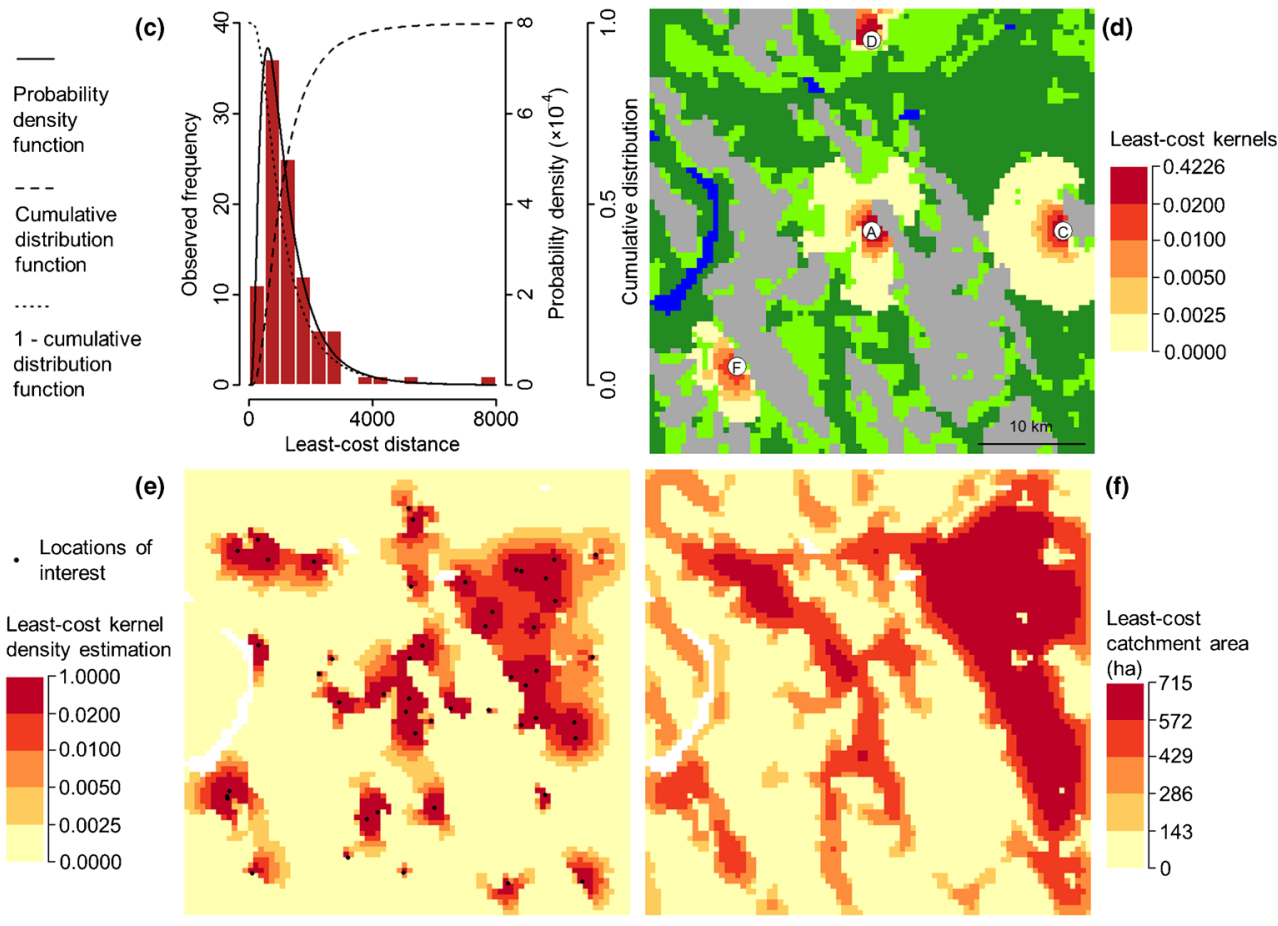

This enables researchers to see not only which patches are connected, but also what parts of the landscape are enabling those connections.

\section{Least-Cost Corridors}

The use of corridors as a means to promote movement between isolated locations has a long-standing interest in ecology [56]. Some ecological studies have defined corridors simply from a least-cost path or by buffering a least-cost path by some Euclidean distance [57]. However, this approach ignores the fact that there are likely to be many alternative least-cost paths with very similar least-cost distances. By creating leastcost surfaces for two locations and then adding these together (Fig. 4b) it is possible to identify the combined least-cost distance to both locations [19], which can be interpreted as a least-cost corridor [44]. However, while least-cost modelling is widely applied as part of corridor planning efforts, there is currently no consensus about how to use a least-cost corridor to delineate reliably a corridor of suitable width [57].

While least-cost corridors identify areas important for maintaining connectivity, methods that can identify locations whose restoration would improve landscape connectivity have also been developed [58]. On a similar theme, least-cost modelling approaches to roadway planning that incorporate the possibility of using bridges and tunnels to reduce traversal costs at key locations have been proposed [59]. Given the increasing use of wildlife under- and over-passes to reduce the costs of crossing roads, such a method could be adapted for an ecological context to identify locations suitable for ecological engineering projects to improve landscape connectivity.

\section{Least-Cost Kernels}

A dispersal distance kernel is a probability density function that is fitted to observations of dispersal in terms of Euclidean 
distance and can be used to describe the probability of an organism dispersing a given Euclidean distance [60]. Dispersal distance kernels form a fundamental component of many ecological studies, as they enable ecologists to transform measures of nearness in terms of Euclidean distance into ecologically meaningful connection probabilities. For the application of least-cost modelling in ecology, ecologists should ideally use least-cost kernels that would enable measures of nearness in terms of least-cost distance to be also turned into ecologically meaningful connection probabilities. While this has rarely been done, all that is required is the same start and end points of dispersal events that are used to define a dispersal distance kernel, but with the dispersal event measured in terms of the least-cost distances between the start and end points of dispersal events [28, 61]. A probability density function can then be fitted to the least-cost distance observations to define a dispersal least-cost distance kernel (Fig. 4c).

Dispersal can also be described in terms of a dispersal location kernel that is the distribution of post-dispersal locations relative to the starting location [60]. In a least-cost context this can be defined as an inverted cumulative distribution function developed from the same set of least-cost distance dispersal observations (Fig. 4c). Then, when applying leastcost modelling to a given location, the least-cost distances from a given location can be rescaled to show the probability that a dispersal event will finish at a given point on the landscape (Fig. 4d).

\section{Least-Cost Kernel Density Estimation}

Ecologists often use kernel density estimation to turn point occurrence data into a continuous probability or density surface, and traditionally this has been done using spatial weighting defined by Euclidean distances [62]. But if a least-cost kernel can be established, then the spatial weighting could be defined by least-cost distances. In an ecological connectivity context, this least-cost kernel density estimation approach was developed to predict areas of importance for dispersal from known dispersal locations such as vernal pools [41], but other important locations such as nest or den sites could equally be used. By fitting a least-cost kernel around each location, the kernels can then be added together to produce a map that shows areas that are more likely to receive dispersers from those locations (Fig. 4e)

\section{Least-Cost Catchment Area Isolation}

The previous least-cost ecological applications require specific locations, such as habitat patches or protected areas, for which movement between the locations is of interest. However, in some landscapes there will be no discrete locations, and instead landscape characteristics such as isolation must be measured as a continuum across the landscape.
Assuming movement can be described in terms of a leastcost kernel, then a catchment area that is within the limits of movement can be generated for any cell of a cost-surface. By iteratively generating a catchment for each cell in the costsurface, the catchment area for each cell can then be visualised to produce a continuous map of intra-landscape isolation (Fig. 4f). This approach was developed in the context of invasive species and zoonotic diseases, where lower levels of isolation would indicate higher risks [5, 25, 27, 63]. But catchment areas could also be used to identify sites with lower levels of isolation that may be more suitable for ecological restoration or species reintroduction.

\section{Ecological Opportunities from Least-Cost Modelling Developments}

\section{Topographic Distance}

Early implementations of least-cost modelling recognised that topography will affect the distance between cells and that changes in elevation should also be taken into account [19]. This can be done by calculating the edge weight $(e)$ of any neighbouring cells ( $a$ and $b$ ) as the mean cost value ( $c$ ) of the neighbouring cells multiplied by the topographic distance that is a function of the Euclidean distance $(d)$ and elevational distance $(z)$ between the centroids of the neighbouring cells:

$e_{a, b}=\frac{c_{a}+c_{b}}{2} \times \sqrt{d_{a, b}^{2} \times z_{a, b}{ }^{2}}$

Topographic distance has rarely been used in ecological applications of least-cost modelling [64], but in landscapes where elevation covers a large range the least-cost distances incorporating topographic distance (Fig. 5b) will differ from least-cost distances using Euclidean distances (Fig. 5a). Therefore, ecologists should consider the potential implications of topographic distances in their least-cost modelling analyses.

\section{Anisotropic Least-Cost Distances}

Thus far, least-cost modelling has been described as an isotropic process. This means that the direction is irrelevant and the cost to traverse a cell is the same regardless of the direction of traversal. In contrast, under anisotropic conditions direction of traversal becomes important, with the traversal cost for a given cell varying depending on the direction of traversal. The importance of anisotropic conditions were noted during the inception of the least-cost modelling idea [16], and while this has received attention in transport geography [59, 65], it has not been incorporated into ecological applications. 
Fig. 5 Comparisons of extensions to (a) the basic leastcost modelling algorithm. (b) The result of measuring distance between neighbouring cells as the topographic distance that incorporates changes in elevation. Anisotropic conditions are imposed for both (c) vertical effects in which moving up slopes is more costly than moving down slopes and (d) horizontal effects in which a prevailing wind makes moving from left to right less costly than moving from right to left. Note the non-linear scale of the least-cost surface distances (a)

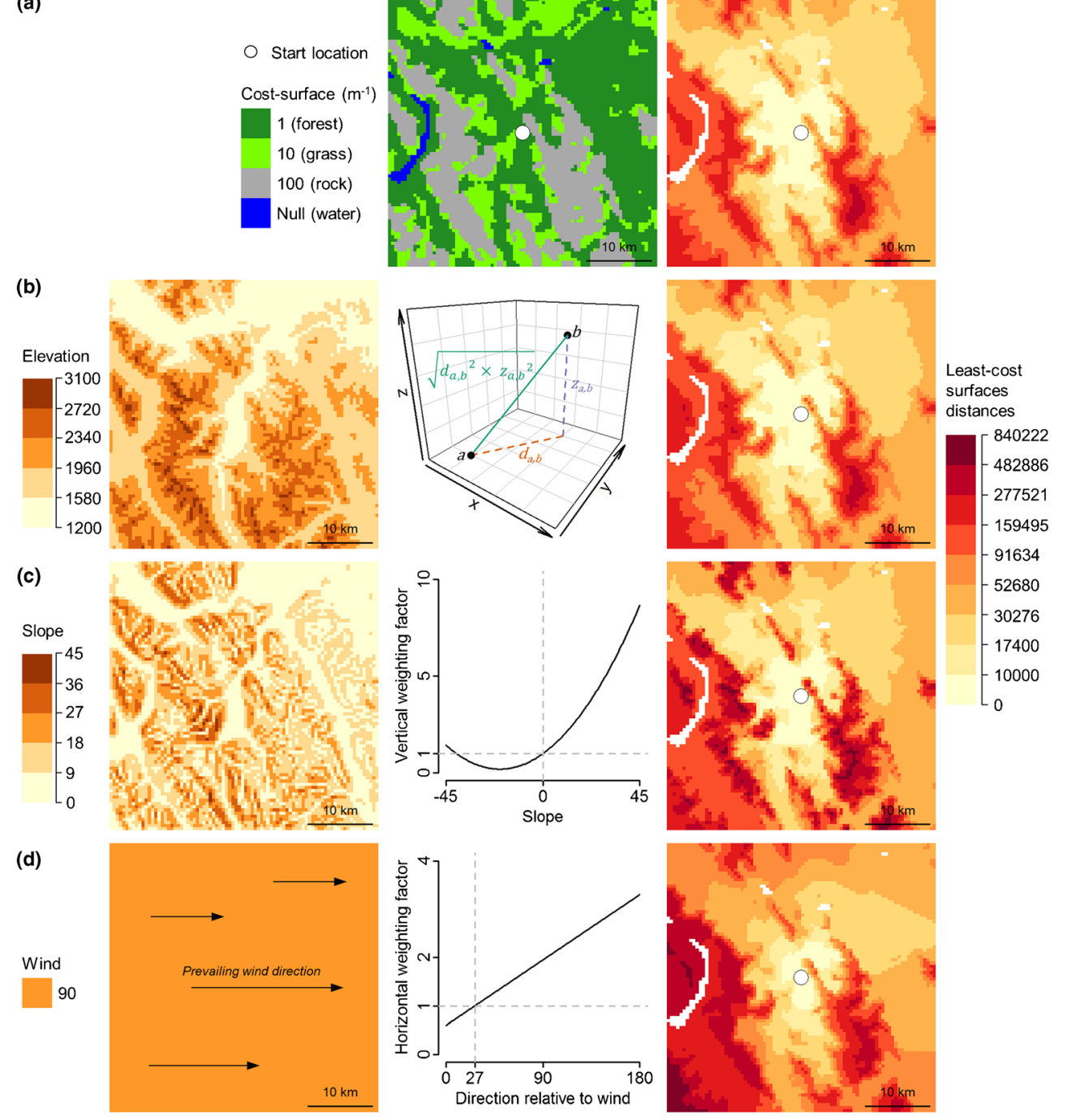

In an ecological context, the potential for anisotropic conditions is perhaps best viewed through the concept of energy landscapes [66•]. Viewing a landscape in terms of energy recognises that vertical movement such as moving uphill or downhill or horizontal movement such as moving upwind or downwind is direction dependent, and hence anisotropic. Zhan et al. [67] described an approach to incorporate vertical and horizontal anisotropy into least-cost modelling through the addition of further vertical $(v)$ and horizontal $(h)$ weighting factors into the edge weighting function:

$e_{a, b}=\frac{c_{a}+c_{b}}{2} \times \sqrt{d_{a, b}^{2} \times z_{a, b}^{2}} \times v_{a, b} \times h_{a, b}$

The vertical weighting factor is derived from the combination of the slope of a vertical gradient field and a rescaling function that describes how traversal costs and hence leastcost distances are affected by movement with or against the vertical gradient (Fig. 5c). The vertical rescaling function can take any form, but will always be equal to one when the slope is zero so that when the vertical gradient is flat there is no effect on the edge weight. The horizontal weighting factor is derived from the combination of a horizontal flow field and a rescaling function of some form that will reduce traversal costs and hence least-cost distances in directions aligned with the horizontal flow, and increase costs and hence least-cost distances in directions aligned against the horizontal flow (Fig. 5d). Given the importance of vertical and horizontal forcing factors on organism movement [66•], incorporating anisotropy into least-cost modelling has the potential to make applications of the technique far more ecologically meaningful.

\section{Raster Data Structure Induced Bias}

While least-cost modelling was first considered using Warntz's $[15,16]$ vector data structure that applied the analogy of refracting light, the raster data structure and graph theory shortest-path algorithm approach developed by Turner and 
Miles [18] has become the predominant least-cost modelling approach used today. This is because the raster approach is computationally much more efficient than the exact vector approach, though it is important to note that the raster approach can only approximate the true leastcost distance due to biases created by the raster data structure itself [68]. The regular shape of the weighted lattice graph created from the raster cost-surface (Fig. 1b) results in zigzagging least-cost paths (Fig. 1e) that are both elongated and deviated from the true least-cost paths [23]. This bias could result in misleading measures of connectivity, but is really only evident when least-cost modelling is applied on a uniform cost-surface when octagonal patterns of spread emerge (Fig. 6). Ecologists should also be aware that some least-cost modelling software provide the option to connect only orthogonal neighbouring cells, rather than diagonally neighbouring cells. However, with only orthogonal neighbours connected, the bias becomes much worse [23, 68, 69] and so should be avoided to minimise the risk of misrepresenting distances.

While this grid-induced bias was noted in the first review of ecological applications of least-cost modelling [22], it has been largely ignored in ecological studies. However, various solutions have been proposed by geographic information scientists. Increasing the number of links between cells to beyond the usual eight orthogonal and diagonal cells produces less biased results [68-70], but requires greater computation times, and results in avoiding single cell width linear features. More complex algorithms that can adjust for angular deviations on a regular grid have also been developed [71, 72], but these are also computationally more demanding. A final option is to convert a raster cost-surface into an irregular data structure to ameliorate the bias [73-76]. A comparison of some of these approaches has indicated that while the effect of grid bias can be reduced, there is unlikely to be an optimum universal solution as the results are dependent on landscape structure [77].

\section{(a)}
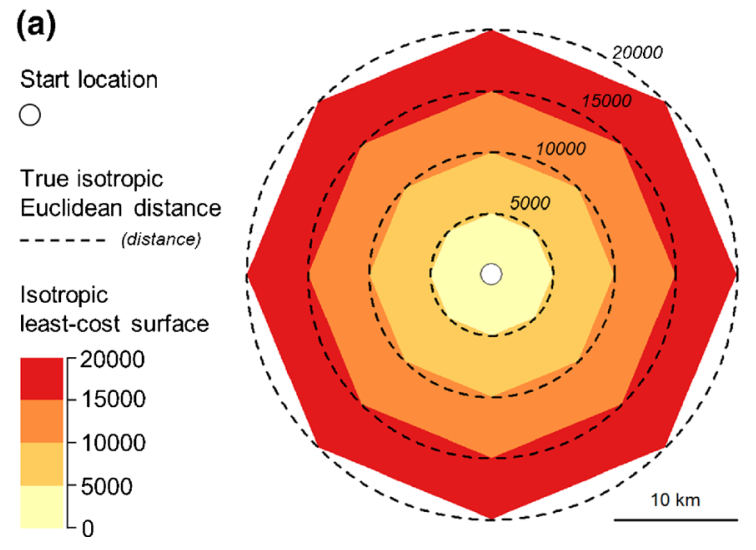

Fig. 6 Examples of the raster induced octagonal bias in least-cost modelling for (a) isotropic conditions, and (b) anisotropic conditions that are the same as those shown in Fig. $5 \mathrm{~d}$. In both cases a uniform

\section{Least-Cost Wide Paths}

A potential problem of least-cost modelling is that owing to the lattice graph structure used to represent the cost-surface (Fig. 1b), the shortest-path graph algorithm that measures the least-cost distances are never more than one cell wide (Fig. 1e), and as such can pass just as easily through a gap one cell wide as a gap that is many cells wide. In an ecological context this means that there is the potential for least-cost distances to be an overly optimistic view of connectivity. When working with invasive species, under a precautionary principle where connectivity is viewed negatively, it would perhaps be better to overestimate the degree of connectivity than underestimate it in order to ensure that all at risk areas are identified. But clearly when attempting to maintain connectivity for conservation applications this could be problematic. Therefore, ecologists may be interested in investigating new least-cost modelling approaches that are designed to find wide least-cost paths $[78,79]$ that may be useful in avoiding issues with least-cost paths being identified through too ecologically narrow landscape elements.

\section{Hierarchical Least-Cost Modelling}

Landscapes are inherently hierarchical, with interactions between different hierarchical levels affecting overall landscape processes [80]. In the context of movement, different hierarchical levels could represent different types of movement. Perhaps the clearest ecological example of hierarchical movement is invasive species for which dispersal is a combination of organism dispersal and human-mediated dispersal via transportation [81], but a similar analogy could be drawn for parasites or diseases that may disperse via a variety of hosts. When movement is likely to result from a hierarchy of different, but inter-connected types of movement, this needs to be recognised within least-cost modelling. There have been efforts to combine different modes of movement to conduct

(b)

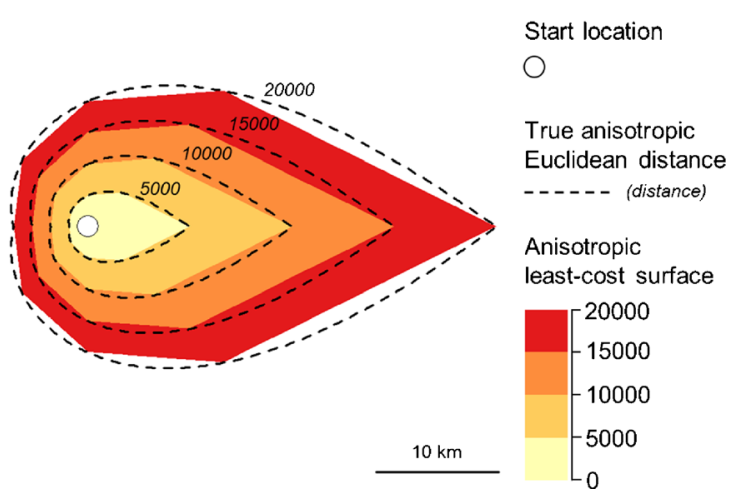

cost-surface with a cost of $1 \mathrm{~m}^{-1}$ has been used so that the least-cost distances should equate to Euclidean distances 
least-cost modelling in a hierarchical context [82] and even in specifically ecological contexts [25]. In both examples leastcost modelling is applied using a hierarchical graph that integrates information from a cost-surface and a transportation network. When using least-cost modelling to measure nearness between locations to infer ecological connectivity and movement, the potential effect of hierarchical interactions could be significant, and this is an area of research that would benefit from further development.

\section{Computational Efficiency for Uncertainty and Sensitivity Analyses}

Cost-surfaces will always be somewhat uncertain, and the need for sensitivity analyses to assess least-cost modelling results was recognised during initial development of the method $[18,83]$. Considering uncertainty is particularly important for ecological applications of least-cost modelling, as the costsurface uncertainties will be much larger than in other applications like transport geography. However, ecological applications have in general included little or no sensitivity analysis, and are often based on expert opinion approaches that will have high levels of uncertainty $[38 \bullet \bullet, 57]$. Ecological studies that have incorporated uncertainty and sensitivity analyses have all done so through repetitive least-cost modelling that varies factors such as costs, scale, and graph structure [28, 39, $40,44,84-87]$. Therefore, beyond the ability of the analyst to program these repetitive analyses, the major obstacle to conducting detailed uncertainty and sensitivity analyses is the computational efficiency of the least-cost modelling.

One approach to reducing computation time is simply to use more powerful forms of computing such as distributed computing $[88,89]$. An alternative is to recognise that leastcost modelling time is primarily a function of the number of cells in the cost-surface being processed and the least-cost path algorithm being used [83].

The number of cells in a cost-surface can be reduced by making the extent smaller or the grain larger [23], although both these approaches may have scaling implications (Fig. 3). An alternative approach is to transform the cost-surface into a sparser irregular network data structure using spatial adaptive aggregation [23], quadtrees [68], or triangulated irregular networks $[75,76]$. These approaches require initial computation time to reduce the complexity of the cost-surface, but if sufficient redundant detail can be removed from the cost-surface, then overall reductions in computation time can be achieved $[75,76]$.

The least-cost modelling approach was defined earlier with reference to Dijkstra's Algorithm [24]. However, there are in fact a range of algorithms, and variations within those algorithms, that can be used to calculate least-cost paths with varying degrees of success depending on the particular analytical requirements and data structure of an analysis [90]. In addition, although heuristic algorithms may not guarantee that an exact least-cost path is found, they have the potential to reduce computation time [91]. Given that in ecological applications no exact least-cost path is likely to exist, it may be beneficial to sacrifice some computational exactness in order to enable greater examination of uncertainty and sensitivity.

Given the high levels of uncertainty present in ecological applications, ecologists should consider leveraging some of these computational approaches to facilitate more robust uncertainty and sensitivity analyses. Having quantified the uncertainty and sensitivity of a least-cost modelling analysis, it is also important to be able to visualise this information in a manner that is useful for the purpose of decision-making, as has been argued for species distribution modelling [92]. There are challenges in visualising uncertainty [93], but this has been done for results from least-cost modelling [40, 63].

\section{Conclusion}

While least-cost modelling was initially developed in the context of transportation geography, there are obvious parallels in an ecological context. Ecologically, higher costs can be used to represent species-specific geographical factors that impede movement via greater mortality risk, energy expenditure, or behavioural aversion. With this perspective, least-cost modelling can be used to produce measures of nearness in terms of least-cost distance that estimate ecological connectivity resulting from the movement process. Such an approach has potential relevance in reference to quantifying the direct transfer costs within a broader dispersal ecology framework [94] or the external factors that influence navigation within the movement ecology framework [95]. Of course, the success of such an endeavour is dependent on the least-cost model that is used. In particular, the conventional isotropic approach that is most commonly used is probably too simplistic a view of movement through a landscape for many organisms, given how energy use during animal movement is often anisotropic [66•]. Therefore, ecologists should endeavour to incorporate findings from the dispersal ecology [94] and movement ecology [95] frameworks by making better use of recent least-cost modelling methodological developments to create least-cost models that are as ecologically meaningful as possible.

While recommending that ecologists endeavour to make more ecologically meaningful least-cost models, it is worth noting that many of the more novel least-cost modelling adaptions that could enable this are not integrated into all GIS software as standard. Therefore, to take advantage of more novel methods, analysts may need to use a variety of software programs, or may have to develop software programs of their own which is possible using high-level programming languages such as Python and R. 
It is also worth noting that least-cost modelling is not the only method that can use a cost-surface as the basis of graph theoretic measures of connectivity. Methods such as circuit theory [96] and network flow [97, 98] have also been presented. Like least-cost modelling, network flow also finds an optimal connectivity solution, but, unlike least-cost modelling, network flow takes into account multiple paths through a graph. In direct contrast to least-cost modelling, which assumes an organism has complete knowledge of a landscape and will select the most optimal route, circuit theory assumes an organism has no knowledge of the landscape and will behave as a random walker. So least-cost modelling, network flow, and circuit theory exist along a spectrum of different connectivity modelling representations and assumptions. As none of the methods will provide a perfect explanation of ecologically connectivity, this raises the question of how to choose between these methods.

Ultimately, the decision about which method to use needs to be based on the individual requirements of a connectivity modelling study, but there are situations in which least-cost modelling may be preferential. Because least-cost modelling is optimistic about connectivity it might be a better methodology for measuring connectivity for invasive species and spread of diseases, as under a precautionary principle where connectivity is viewed negatively, it would be better to overestimate the degree of connectivity than under-predict it. Also, given the recommendations to explicitly consider uncertainty, a technique is required that is computationally efficient enough to assess outcomes under different conditions. With this requirement in mind, least-cost modelling may provide a more reasonable balance between theoretical complexity and computational simplicity. Finally, as network flow and circuit theory are both one-to-one connectivity methods that measure connectivity between specific source and sink locations, they cannot currently be used to define outputs such dispersal kernels (Fig. 4d) for kernel density estimation (Fig. 4e) or catchment area (Fig. 4f) maps. In contrast, least-cost modelling as a one-to-all connectivity method that measures connectivity outwards from a single source location is required. Therefore, even with the availability of more recent developments in connectivity modelling in landscape ecology, leastcost modelling is likely to be used extensively within future landscape ecology research. Hopefully this review has highlighted useful least-cost modelling connections between landscape ecology and geographical information science and will encourage ecologists to make use of recent developments that have potential ecological applications.

\section{Compliance with Ethical Standards}

Conflict of Interest On behalf of all authors, the corresponding author states that there is no conflict of interest.
Human and Animal Rights and Informed Consent This article does not contain any studies with human or animal subjects.

\section{References}

Papers of particular interest, published recently, have been highlighted as:

- Of importance

•- Of major importance

1. Kuhn W. Core concepts of spatial information for transdisciplinary research. Int J Geogr Inf Sci. 2012;26(12):2267-76.

2. Tobler W. A computer movie simulating urban growth in the Detroit region. Econ Geogr. 1970;46(2):234 40.

3. Miller HJ. Tobler's First Law and Spatial Analysis. Ann Assoc Am Geogr. 2004;94(2):284-9.

4. Fahrig L. Effects of habitat fragmentation on biodiversity. Annu Rev Ecol Evol Syst. 2003;34:487-515.

5. Etherington TR. Geographical isolation and invasion ecology. Prog Phys Geogr. 2015;39(6):697-710.

6. Glen AS, Pech RP, Byrom AE. Connectivity and invasive species management: towards an integrated landscape approach. Biol Invasions. 2013;15(10):2127-38.

7. Meentemeyer RK, Haas SE, Václavík T. Landscape epidemiology of emerging infectious diseases in natural and human-altered ecosystems. Annu Rev Phytopathol. 2012;50:379-402.

8. Ostfeld RS, Glass GE, Keesing F. Spatial epidemiology: an emerging (or re-emerging) discipline. Trends Ecol Evol. 2005;20(6):32836.

9. MacArthur RH, Wilson EO. The theory of island biogeography. Princeton University Press: Princeton; 1967.

10. Forman RTT, Godron M. Patches and structural components for a landscape ecology. Bioscience. 1981;31(10):733-40.

11. Opdam P, Van Dorp D, Ter Braak CJF. The effect of isolation on the number of woodland birds in small woods in the Netherlands. $\mathrm{J}$ Biogeogr. 1984;11(6):473-8.

12. Thomas CD, Thomas JA, Warren MS. Distributions of occupied and vacant butterfly habitats in fragmented landscapes. Oecologia. 1992;92(4):563-7.

13. Taylor PD, Fahrig L, Henein K, Merriam G. Connectivity is a vital element of landscape structure. Oikos. 1993;68(3):571-3.

14. Ricketts TH. The matrix matters: effective isolation in fragmented landscapes. Am Nat. 2001;158(1):87-99.

15. Warntz W. Transportation, social physics, and the law of refraction. Prof Geogr. 1957;9(4):2-7.

16. Warntz W. A note on surfaces and paths and applications to geographical problems. Ann Arbor: Michigan Inter-University Community of Mathematical Geographers; 1965.

17. McHarg I. Where should highways go? Landsc Archit. 1967;57(3): 179-81.

18. Turner AK, Miles RD. The GCARS System: a computer-assisted method of regional route location. Highw Res Rec. 1971;348:1-15.

19. Tomlin CD. Geographic Information Systems and Cartographic Modeling. Englewood Cliffs: Prentice-Hall; 1990.

20. Chardon JP, Adriaensen F, Matthysen E. Incorporating landscape elements into a connectivity measure: a case study for the Speckled wood butterfly (Pararge aegeria L.). Landsc Ecol. 2003;18(6): 561-73.

21. Verbeylen G, De Bruyn L, Adriaensen F, Matthysen E. Does matrix resistance influence red squirrel (Sciurus vulgaris L. 1758) distribution in an urban landscape? Landsc Ecol. 2003;18(8):791-805. 
22. Adriaensen F, Chardon JP, De Blust G, Swinnen E, Villalba S, Gulinck H, et al. The application of 'least-cost' modelling as a functional landscape model. Landsc Urban Plan. 2003;64(4):233-47.

23. Goodchild MF. An evaluation of lattice solutions to the problem of corridor location. Environ Plan A. 1977;9(7):727-38.

24. Dijkstra EW. A note on two problems in connexion with graphs. Numer Math. 1959;1(1):269-71.

25. Etherington TR. Mapping organism spread potential by integrating dispersal and transportation processes using graph theory and catchment areas. Int J Geogr Inf Sci. 2012;26(3):541-56.

26. Etherington TR, Holland EP. Least-cost path length versus accumulated-cost as connectivity measures. Landsc Ecol. 2013;28(7):1223-9.

27. Etherington TR, Trewby ID, Wilson GJ, McDonald RA. Expert opinion-based relative landscape isolation maps for badgers across England and Wales. Area. 2014;46(1):50-8.

28. Etherington TR, Perry GLW, Cowan PE, Clout MN. Quantifying the direct transfer costs of common brushtail possum dispersal using least-cost modelling: a combined cost-surface and accumulated-cost dispersal kernel approach. PLoS One. 2014;9(2):e88293.

29. Trainor AM, Walters JR, Morris WF, Sexton J, Moody A. Empirical estimation of dispersal resistance surfaces: a case study with redcockaded woodpeckers. Landsc Ecol. 2013;28(4):755-67.

30. Foltête J-C, Berthier K, Cosson JF. Cost distance defined by a topological function of landscape. Ecol Modell. 2008;210(1-2): 104-14.

31. Richard Y, Armstrong DP. Cost distance modelling of landscape connectivity and gap-crossing ability using radio-tracking data. J Appl Ecol. 2010;47(3):603-10.

32. Rothley K. Finding and filling the "cracks" in resistance surfaces for least-cost modeling. Ecol Soc. 2005;10(1):4.

33. Theobald DM. A note on creating robust resistance surfaces for computing functional landscape connectivity. Ecol Soc. 2005;10(2):r1.

34. Dean DJ. Optimal routefinding across landscapes featuring highcost linear obstacles. Trans GIS. 2015. doi:10.1111/tgis.12170.

35. Wiens JA. Spatial scaling in ecology. Funct Ecol. 1989;3(4):38597.

36. Cushman SA, Landguth EL. Scale dependent inference in landscape genetics. Landsc Ecol. 2010;25(6):967-79.

37. Liu W, Chen D, Scott NA. Effects of cell sizes on resistance surfaces in GIS-based cost distance modeling for landscape analyses. In: Gong P, Liu Y, editors. Geoinformatics 2007: Geospatial Information Technology and Applications; May 25-27; Nanjing, China. Bellingham, WA: SPIE; 2007. p. 6754-19.

38.• Zeller KA, McGarigal K, Whiteley AR. Estimating landscape resistance to movement: a review. Landsc Ecol. 2012;27(6):777-97.

This review presents a very thorough assessment of the ecological applications of least-cost modelling. Topics covered include: taxonomic bias, environmental variables, biological data, and analytical approaches. The supplementary material also provides a list of ecological studies and approaches that make a useful reference resource.

39. Beier P, Majka DR, Newell SL. Uncertainty analysis of least-cost modeling for designing wildlife linkages. Ecol Appl. 2009;19(8): 2067-77.

40. Bunn AG, Urban DL, Keitt TH. Landscape connectivity: a conservation application of graph theory. J Environ Manage. 2000;59(4): 265-78.

41. Compton BW, McGarigal K, Cushman SA, Gamble LR. A resistant-kernel model of connectivity for amphibians that breed in vernal pools. Conserv Biol. 2007;21(3):788-99.

42. Eycott AE, Marzano M, Watts K. Filling evidence gaps with expert opinion: the use of Delphi analysis in least-cost modelling of functional connectivity. Landsc Urban Plan. 2011;103(3-4):400-9.
43. Watts K, Eycott AE, Handley P, Ray D, Humphrey JW, Quine CP. Targeting and evaluating biodiversity conservation action within fragmented landscapes: an approach based on generic focal species and least-cost networks. Landsc Ecol. 2010;25(9):1305-18.

44. Pinto N, Keitt TH. Beyond the least-cost path: evaluating corridor redundancy using a graph-theoretic approach. Landsc Ecol. 2009;24(2):253-66.

45. Manel S, Holderegger R. Ten years of landscape genetics. Trends Ecol Evol. 2013;28(10):614-21.

46. Spear SF, Balkenhol N, Fortin M-J, McRae BH, Scribner K. Use of resistance surfaces for landscape genetic studies: considerations for parameterization and analysis. Mol Ecol. 2010;19(17):3576-91.

47. Cushman SA, McKelvey KS, Hayden J, Schwartz MK. Gene flow in complex landscapes: testing multiple hypotheses with causal modeling. Am Nat. 2006;168(4):486-99.

48. Graves TA, Beier P, Royle JA. Current approaches using genetic distances produce poor estimates of landscape resistance to interindividual dispersal. Mol Ecol. 2013;22(15):3888-903.

49. Goldberg CS, Waits LP. Comparative landscape genetics of two pond-breeding amphibian species in a highly modified agricultural landscape. Mol Ecol. 2010;19(17):3650-63.

50. Balkenhol N, Waits LP, Dezzani RJ. Statistical approaches in landscape genetics: an evaluation of methods for linking landscape and genetic data. Ecography. 2009;32(5):818-30.

51. Olden JD, Lawler JJ, Poff NL. Machine learning methods without tears: a primer for ecologists. Q Rev Biol. 2008;83(2):171-93.

52. Zurell D, Berger U, Cabral JS, Jeltsch F, Meynard CN, Münkemüller T, et al. The virtual ecologist approach: simulating data and observers. Oikos. 2010;119(4):622-35. A introduction to the virtual ecology framework that provides much promise for the development of methods that integrate least-cost modelling with ecological data.

53. Miller JA. Virtual species distribution models: using simulated data to evaluate aspects of model performance. Prog Phys Geogr. 2014;38(1):117-28.

54. Cantwell MD, Forman RTT. Landscape graph: ecological modeling with graph theory to detect configurations common to diverse landscapes. Landsc Ecol. 1993;8(4):239-55.

55. Urban DL, Minor ES, Treml EA, Schick RS. Graph models of habitat mosaics. Ecol Lett. 2009;12(3):260-73.

56. Rosenberg DK, Noon BR, Meslow EC. Biological corridors: form, function, and efficacy. Bioscience. 1997;47(10):677-87.

57. Sawyer SC, Epps CW, Brashares JS. Placing linkages among fragmented habitats: do least-cost models reflect how animals use landscapes? J Appl Ecol. 2011;48(3):668-78.

58. McRae BH, Hall SA, Beier P, Theobald DM. Where to restore ecological connectivity? Detecting barriers and quantifying restoration benefits. PLoS One. 2012;7(12):e52604.

59. Yu C, Lee J, Munro-Stasiuk MJ. Extensions to least-cost path algorithms for roadway planning. Int J Geogr Inf Sci. 2003;17(4):36176.

60. Nathan R, Klein E, Robledo-Arnuncio JJ, Revilla E. Dispersal kernels: review. In: Clobert J, Baguette M, Benton TG, Bullock JM, editors. Dispersal Ecology and Evolution. Oxford: Oxford University Press; 2012. p. 187-210.

61. Graves T, Chandler RB, Royle JA, Beier P, Kendall KC. Estimating landscape resistance to dispersal. Landsc Ecol. 2014;29(7):120111 .

62. Nelson TA, Boots B. Detecting spatial hot spots in landscape ecology. Ecography. 2008;31(5):556-66.

63. Etherington TR, Perry GLW. Visualising continuous intralandscape isolation with uncertainty using least-cost modelling based catchment areas: common brushtail possums in the Auckland isthmus. Int J Geogr Inf Sci. 2016;30(1):36-50. 
64. Vignieri SN. Streams over mountains: influence of riparian connectivity on gene flow in the Pacific jumping mouse (Zapus trinotatus). Mol Ecol. 2005;14(7):1925-37.

65. Collischonn W, Pilar JV. A direction dependent least-cost-path algorithm for roads and canals. Int J Geogr Inf Sci. 2000;14(4):397406.

66. Shepard ELC, Wilson RP, Rees WG, Grundy E, Lambertucci SA, Vosper SB. Energy landscapes shape animal movement ecology. Am Nat. 2013;182(3):298-312. A very thought provoking paper that highlights the importance of anisotropic forces on organism movement. Many of the arguments and ideas have direct analogies in a least-cost modelling context and so could be easily incorporated into ecological analyses.

67. Zhan C, Menon S, Gao P. A directional path distance model for raster distance mapping. In: Frank AU, Campari I, editors. Spatial Information Theory: a theoretical basis for GIS. Berlin: SpringerVerlag; 1993. p. 434-43.

68. van Bemmelen J, Quak W, van Hekken M, van Oosterom P. Vector vs. raster-based algorithms for cross country movement planning. In: McMaster RB, Armstrong MP, editors. Proceedings of the International Symposium on Computer-Assisted Cartography (Auto-Carto XI); October 30 - November 1 1993; Minneapolis, Minnesota. Bethesda, Maryland American Society for Photogrammetry and Remote Sensing and American Congress on Surveying and Mapping; 1993. p. 304-17.

69. Xu J, Lathrop RG. Improving simulation accuracy of spread phenomena in a raster-based geographic information system. Int $\mathrm{J}$ Geogr Inf Sci. 1995;9(2):153-68.

70. $\mathrm{Xu}$ J, Lathrop RG. Improving cost-path tracing in a raster data format. Comput Geosci. 1994;20(10):1455-65.

71. Douglas DH. Least-cost path in GIS using an accumulated cost surface and slopelines. Cartographica. 1994;31(3):37-51.

72. Tomlin D. Propagating radial waves of travel cost in a grid. Int J Geogr Inf Sci. 2010;24(9):1391-413.

73. Dean DJ. Optimal routefinding with unlimited possible directions of movement. Trans GIS. 2011;15(1):87-107.

74. Dunn AG. Grid-induced biases in connectivity metric implementations that use regular grids. Ecography. 2010;33(3): 627-31.

75. Etherington TR. Least-cost modelling on irregular landscape graphs. Landsc Ecol. 2012;27(7):957-68.

76. Stachelek J. [Re] Least-cost modelling on irregular landscape graphs. ReScience. 2016;2(1):1-4.

77. Antikainen H. Comparison of different strategies for determining raster-based least-cost paths with a minimum amount of distortion. Trans GIS. 2013;17(1):96-108.

78. Gonçalves AB. An extension of GIS-based least-cost path modelling to the location of wide paths. Int J Geogr Inf Sci. 2010;24(7): 983-96.

79. Shirabe T. A method for finding a least-cost wide path in raster space. Int J Geogr Inf Sci. 2015;30(8):1469-85.

80. Urban DL, O'Neill RV, Shugart HH. Landscape ecology: a hierarchical perspective can help scientists understand spatial patterns. Bioscience. 1987;37(2):119-27.
81. Auffret AG, Berg J, Cousins SAO. The geography of humanmediated dispersal. Divers Distrib. 2014;20(12):1450-6.

82. Choi Y, Um J-G, Park M-H. Finding least-cost paths across a continuous raster surface with discrete vector networks. Cartogr Geogr Inf Sci. 2014;41(1):75-85.

83. Turner AK. A decade of experience in computer aided route selection. Photogramm Eng Remote Sens. 1978;44(12):1561-76.

84. Gonzales EK, Gergel SE. Testing assumptions of cost surface analysis - a tool for invasive species management. Landsc Ecol. 2007;22(8):1155-68.

85. Rae C, Rothley K, Dragicevic S. Implications of error and uncertainty for an environmental planning scenario: a sensitivity analysis of GIS-based variables in a reserve design exercise. Landsc Urban Plan. 2007;79(3-4):210-7.

86. Rayfield B, Fortin M-J, Fall A. The sensitivity of least-cost habitat graphs to relative cost surface values. Landsc Ecol. 2010;25(4): 519-32.

87. Schadt S, Knauer F, Kaczensky P, Revilla E, Wiegand T, Trepl L. Rule-based assessment of suitable habitat and patch connectivity for the Eurasian lynx. Ecol Appl. 2002;12(5):1469-83.

88. Hazel T, Toma L, Vahrenhold J, Wickremesinghe R. Terracost: computing least-cost-path surfaces for massive grid terrains. ACM Journal of Experimental Algorithmics. 2008;12:Article 1.9.

89. Kovanen J, Sarjakoski T. Tilewise accumulated cost surface computation with graphics processing units. ACM Transactions on Spatial Algorithms and Systems. 2015;1(2):Article 8.

90. Zhan FB, Noon CE. Shortest path algorithms: an evaluation using real road networks. Transp Sci. 1998;32(1):65-73.

91. Antikainen A. Using the hierarchical pathfinding $A^{*}$ algorithm in GIS to find paths through rasters with nonuniform traversal cost. ISPRS Int J Geo-Inf. 2013;2(4):996-1014.

92. Rocchini D, Hortal J, Lengyel S, Lobo JM, Jiménez-Valverde A, Ricotta $\mathrm{C}$, et al. Accounting for uncertainty when mapping species distributions: the need for maps of ignorance. Prog Phys Geogr. 2011;35(2):211-26

93. MacEachren AM, Robinson A, Hopper S, Gardner S, Murray R, Gahegan M, et al. Visualizing geospatial information uncertainty: what we know and what we need to know. Cartogr Geogr Inf Sci. 2005;32(3):139-60.

94. Bonte D, Van Dyck H, Bullock JM, Coulon A, Delgado M, Gibbs M, et al. Costs of dispersal. Biol Rev. 2012;87(2):290-312.

95. Nathan R, Getz WM, Revilla E, Holyoak M, Kadmon R, Saltz D, et al. A movement ecology paradigm for unifying organismal movement research. Proc Natl Acad Sci U S A. 2008;105(49):19052-9.

96. McRae BH, Dickson BG, Keitt TH, Shah VB. Using circuit theory to model connectivity in ecology, evolution, and conservation. Ecology. 2008;89(10):2712-24.

97. Carroll C, McRae BH, Brookes A. Use of linkage mapping and centrality analysis across habitat gradients to conserve connectivity of gray wolf populations in western North America. Conserv Biol. 2012;26(1):78-87.

98. Phillips SJ, Williams P, Midgley G, Archer A. Optimizing dispersal corridors for the Cape Proteaceae using network flow. Ecol Appl. 2008;18(5):1200-11. 